\title{
PETRIJEVE MREŽE I SIMULACIJE PROIZVODNIH SISTEMA I PROCESA
}

\author{
Dr Milorad Rančić \\ Visoka tehnička škola Zrenjanin \\ e-mail: rancicmil@ptt.rs \\ Dušan Rančić, dipl.maš.inž. \\ IMK „14.OKTOBAR“, Kruševac \\ e-mail: rancic_dusan@yahoo.com
}

\section{Sažetak}

Petrijeve mreže su moćan grafo-analitički matematički aparat koji može da ima široku primenu u oblasti modeliranja, analize i sinteze različitih sistema. U ovom radu su izložene njihove osnovne definicije i osobine. Ukazuje se na mogućnost primene kod simulacije proizvodnih sistema i procesa. Kao ilustracija prikazani su konkretni primeri.

\section{Abstract}

Petri Nets are powerful grapho-analytical and mathematical tools that can be widely used in the fields of modelling, analysis and synthesis of various systems. This paper presents us with the definition itself and their basic properties. These are possible to use in the simulation of manufacturing systems and processes. Specific examples above serve as the illustration.

Ključne reči: Petrijeve mreže, grafovi, simulacije, proizvodni sistemi.

Keywords: Petri Nets, graphs, simulation, manufacturing systems.

\section{Uvod}

Petrijeve mreže su poslednjih godina imale veoma buran razvoj. Postale su efikasan grafoanalitički aparat sa širokom primenom kao što su to npr. analitička i simulaciona istraživanja, modeliranje asinhronih, diskretnih i stohastičkih procesa, analiza ponašanja i sinteza različitih sistema. Njihov razvoj uglavnom je išao u pravcu čiste i primenjene teorije. Čista teorija Petrijevih mreža bavi se razvojem osnovnih pojmova, metoda i sredstava neophodnih za njihovu primenu. Veliki broj radova iz ove oblasti odnosi se na fundamentalnu teoriju. Razvijene su metode i sredstva koja su se pokazala korisnim za primenu u konkretnim uslovima i realnim zadacima. Primenjena teorija Petrijevih mreža vezana je za primenu pri modeliranju sistema, njihovu analizu i dobijanje rezultata koji ulaze u suštinu ponašanja sistema. Do danas je razvijen veliki broj različitih vrsta Petrijevih mreža: obične, crno-bele, obojene, vremenske, stohastičke, modularne itd. U stručnoj literaturi se neprestano pojavljuju nove klase. Neke vrste su postale i standardni modeli - npr. u oblastima informatike i upravljačke tehnike.

Za praktičnu primenu Petrijevih mreža pri projektovanju i analizi sistema moguće je više prilaza. $U$ jednom od njih Petrijeva mreža predstavlja pomoćni instrument analize. Za formiranje sistema koriste se opšte poznate metode projektovanja. Zatim se za formirani sistem modelira Petrijeva 
mreža i model analizira. U analizi se ukazuje na teškoće i nedostatke u projektu i vrše njegove izmene. Izmenjeni sistem se ponovo modelira i analizira. Ciklus se ponavlja sve dok analize ne dovedu do željenog cilja. Ovakav prikaz ilustrovan je na slici $1 \mathrm{i}$ on se može koristiti i za analizu već postojećih sistema koji funkcionišu.

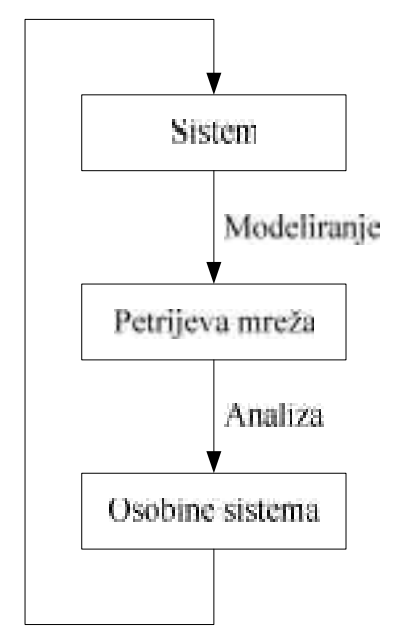

Slika 1. Jedan prilaz pri projektovanju i analizi sistema

Ovo je opšte prihvaćeni prilaz korišćenja PM - a pri projektovanju kod koga se vrši višestruko pretvaranje projektovanog sistema u model u obliku Petrijeve mreže.

Modeli Petrijevih mreža imaju prednosti koje se sastoje u tome što se dinamička, sekvencijalna i paralelna dešavanja heterogenih geneza pregledno predstavljaju. Mogu se definisati i simulirati različita stanja i procesi, opisivati protok informacija. $\mathrm{S}$ obzirom na različite namene $\mathrm{i}$ zahteve za mnoge klase PM - a razvijeni su algebarski i grafoanalitički postupci i metode. Glavni nedostatak Petrijevih mreža jeste njihova nepreglednost u slučaju opisa velikih i kompleksnih sistema.

\section{Struktura Petrijeve mreže}

Petrijeva mreža (PM) predstavlja, kako je već rečeno, apstraktni prikaz procesa kod koga su uspostavljeni vremenski i uzročni međuodnosi. Definicija PM-a može biti neformalna i formalna, i može se izvesti na više načina.
S obzirom da ima više varijanti Petrijevih mreža za sve njih postoje zajednički elementi i njih čine:

- pozicije (stanja sistema)

- tranzicije (prelazi iz jednog stanja u drugo)

- usmerene grane (usmerene linije elementi koji povezuju pozicije i tranzicije)

- markiranje (markeri, marke)

Svi elementi Petrijeve mreže ustvari čine jedan graf, odnosno, multigraf za koga važi sledeće:

- graf je usmeren (digraf)

- čvorovi grafa imaju dva oblika poziciju i tranziciju

- pozicije su povezane samo sa tranzicijom (i obrnuto) usmerenim linijama, odnosno, usmerenim granama

- usmerene grane između dve pozicije (ili tranzicije) nisu dozvoljene

- pozicije mogu biti markirane

Struktura Petrijeve mreže definisana je njenim pozicijama, tranzicijama, usmerenim granama i markerima.

Izlažu se definicije osnovnih pojmova:

\section{Definicija 1.}

Formalno se Petrijeva mreža, prema [1], definiše kao uređen skup šestorki $\mathrm{PM}=(\mathrm{P}, \mathrm{T}, \mathrm{F}, \mathrm{M}, \mathrm{K}, \mathrm{W})$ gde su:

$\mathrm{P}=\left\{\mathrm{p}_{1}, \mathrm{p}_{2}, \ldots, \mathrm{p}_{|\mathrm{P}|}\right\}-$ konačan skup pozicija;

$\mathrm{T}=\left\{\mathrm{t}_{1}, \mathrm{t}_{2}, \ldots, \mathrm{t}_{|\mathrm{T}|}\right\}-$ konačan skup tranzicija;

$\mathrm{F} \subseteq(\mathrm{P} \times \mathrm{T}) \cup(\mathrm{T} \times \mathrm{P}) \quad-\quad$ konačan skup orjentisanih grana (linija) koga čine grane pre i posle tranzicije;

$\mathrm{K}$ - kapacitet pozicija;

$\mathrm{W}$ - težine orjentisanih grana (linija);

M - markiranje (broj markera u poziciji);

uz uslov da je $\mathrm{P} \cap \mathrm{T} \neq \varnothing$.

Pozicije $P_{i}$ su pasivni elementi mreže. Tranzicije $T_{j}$ su aktivni elementi koji tzv. okidanjem prouzrokuju tok markera kroz Petrijevu mrežu. Pozicijama se dodeljuju dva prirodna broja $\mathrm{K}$ i $\mathrm{M}$, a orjentisanim 
granama broj W. Pozicija može imati jedan ili više markera. Kapacitet pozicije je označen brojem K i predstavlja broj markera koje odgovarajuća pozicija može da sadrži. Broj M označava koliko stvarnih markera pozicija sadrži. Tranzicije nemaju dodatne parametre. One su aktivni elementi pošto se njihovom aktivnošću menja raspored markera $u$ pozicijama, što se naziva „okidanje“ (nemački schalten, engleski firing, ruski zapuska).

Težine dodeljene orjentisanoj grani (usmerenoj liniji) označene sa W predstavljaju broj markera koji protiču granom pri okidanju tranzicije.

Sa $M o$ može da se označi početno, inicijalno markiranje.

Neobeležena (neopterećena) grana prema konvenciji poseduje težinu 1.

Petrijeva mreža koja nije markirana označava se sa $\mathrm{N}=(\mathrm{P}, \mathrm{T}, \mathrm{F})$. Zato može da se napiše $\mathrm{PM}=(\mathrm{N}, \mathrm{M}, \mathrm{K}, \mathrm{W})$. U slučaju da su sve težine jednake 1 za Petrijevu mrežu N kaže se da je to obična (ordinary) Petrijeva mreža (simple, jednostavna, čista PM) [1].

Struktura Petrijeve mreže može biti definisana i na nešto drugačiji način.

\section{Definicija 2.}

Petrijeva mreža je, prema [2], [3], petorka $\mathrm{PM}=(\mathrm{P}, \mathrm{T}, \mathrm{U}, \mathrm{I}, \mu)$ gde su:

$\mathrm{P}=\left\{\mathrm{p}_{1}, \mathrm{p}_{2}, \ldots, \mathrm{p}_{\mathrm{n}}\right\}, \mathrm{n} \geq 0 \quad-\quad$ konačan skup pozicija;

$\mathrm{T}=\left\{\mathrm{t}_{1}, \mathrm{t}_{2}, \ldots, \mathrm{t}_{\mathrm{m}}\right\}, \mathrm{m} \geq 0 \quad-\quad$ konačan skup tranzicija;

Skup pozicija i skup tranzicija se ne seku: $\mathrm{P} \cap \mathrm{T} \neq 0$.

$\mathrm{U}: \mathrm{T} \rightarrow \mathrm{P}$ - ulazna funkcija - preslikava tranzicije u pozicije;

$\mathrm{I}: \mathrm{P} \rightarrow \mathrm{T}$ - izlazna funkcija - preslikava pozicije u tranzicije;

$\mu=\left(\mu_{1}, \mu_{2}, \ldots, \mu_{n},\right)-$ markiranje - vektor koji definiše broj i raspored marki (markera, tačaka) u pozicijama mreže.

\section{Graf Petrijeve mreže}

Za ilustraciju mnogih pojmova iz teorije Petrijevih mreža veoma je pogodno grafičko predstavljanje. Zato se pri grafičkom predstavljanju Petrijeve mreže koristi orjentisan graf, odnosno, multigraf.

S obzirom da strukturu Petrijeve mreže čini sveukupnost pozicija i tranzicija, graf Petrijeve mreže sadrži dva tipa čvorova: pozicije i tranzicije. Kružići O predstavljaju pozicije a poprečne crte \| predstavljaju tranzicije. Orjentisane grane povezuju pozicije i tranzicije pri čemu su neke usmerene od pozicije ka tranzicijama, a neke od tranzicije ka pozicijama. Grana usmerena od pozicije $p_{i}$ ka tranziciji $t_{j}$ definiše poziciju koja predstavlja ulaz tranzicije. Izlazna pozicija predstavlja se kao grana od tranzicije ka poziciji. Petrijeva mreža je multigraf zato što on dopušta postojanje zajedničkih grana od jednog čvora grafa ka drugom. Pošto su takve grane usmerene, onda se radi o orjentisanom multigrafu. Radi boljeg razumevanja, on ce se nadalje nazivati Petrijev graf.

Prema prethodnom izlaganju definicija grafa Petrijeve mreže može imati sledeći oblik:

Graf G Petrijeve mreže je orjentisan multigraf $\mathrm{G}=(\mathrm{V}, \mathrm{A})$ gde su:

$$
\begin{aligned}
& \mathrm{V}=\left\{\mathrm{v}_{1}, \mathrm{v}_{2}, \ldots, \mathrm{v}_{\mathrm{s}}\right\}-\text { skup čvorova; } \\
& \mathrm{A}=\left\{\mathrm{a}_{1}, \mathrm{a}_{2}, \ldots, \mathrm{a}_{\mathrm{r}}\right\}-\text { skup orjentisanih }
\end{aligned}
$$
grana.

Skup V se može razbiti na dva podskupa P i T koji se ne seku, takva da je:

$$
\begin{aligned}
& \mathrm{V}=\mathrm{P} \cup \mathrm{T}, \quad \mathrm{P} \cap \mathrm{T}=\varnothing \\
& \mathrm{P}-\text { podskup (skup) pozicija, } \\
& \mathrm{T}-\text { podskup (skup) tranzicija. }
\end{aligned}
$$




\section{Primeri grafova Petrijevih mreža za zadate strukture}

\section{Primer 1.}

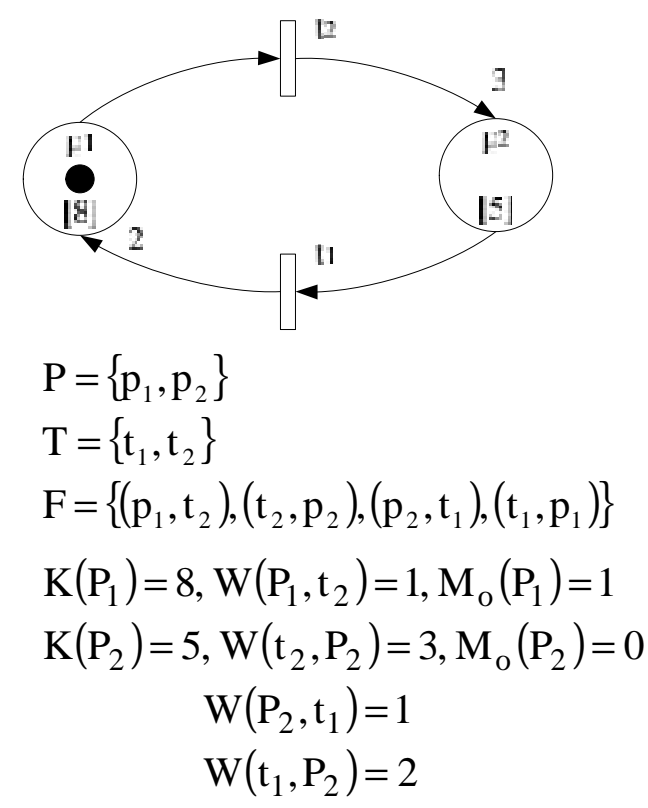

Slika 2. Primer Petrijevog grafa

\section{Primer 2.}

$$
\begin{aligned}
P= & \left\{p_{1}, p_{2}, p_{3}, p_{4}, p_{5}\right\} \\
T=\{ & \left\{t_{1}, t_{2}, t_{3}, t_{4}\right\} \\
F= & \left\{\left(p_{1}, t_{1}\right),\left(t_{1}, p_{2}\right),\left(t_{1}, p_{3}\right),\left(t_{1}, p_{5}\right),\right. \\
& \left(p_{2}, t_{2}\right),\left(t_{2}, p_{5}\right),\left(p_{3}, t_{2}\right),\left(p_{3}, t_{3}\right), \\
& \left.\left(t_{3}, p_{4}\right),\left(p_{4}, t_{4}\right),\left(t_{4}, p_{2}\right),\left(t_{4}, p_{3}\right),\left(p_{5}, t_{2}\right)\right\}
\end{aligned}
$$

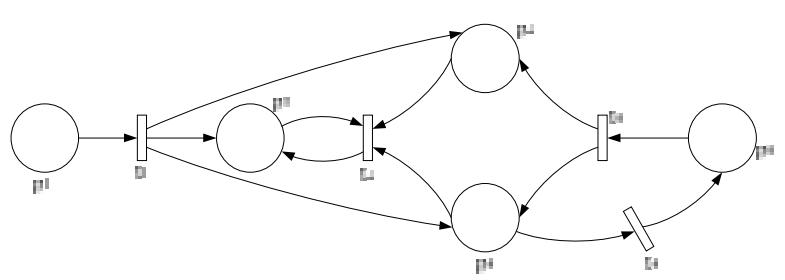

Slika 3. Graf Petrijeve mreže za zadatu strukturu u primeru 2.

Na slici 2 i slici 3, prikazani su Grafovi Petrijevih mreža za zadate strukture kod kojih težine orjentisanih grana imaju vrednost 1 , a pozicije nisu markirane.

Strukture Petrijeve mreže iz Primera 1 i Primera 2 mogu se na osnovu Definicije 2, prikazati i na drugačiji način.
Za Primer 1. to će biti:

$$
\begin{aligned}
& \mathrm{P}=\left\{\mathrm{p}_{1}, \mathrm{p}_{2}, \mathrm{p}_{3}, \mathrm{p}_{4}\right\} \\
& \mathrm{T}=\left\{\mathrm{t}_{1}, \mathrm{t}_{2}, \mathrm{t}_{3}, \mathrm{t}_{4}\right\}
\end{aligned}
$$

$$
\begin{array}{ll}
\mathrm{U}\left(\mathrm{t}_{1}\right)=\left\{\mathrm{p}_{1}\right\} & \mathrm{I}\left(\mathrm{p}_{1}\right)=\left\{\mathrm{t}_{1}\right\} \\
\mathrm{U}\left(\mathrm{t}_{2}\right)=\left\{\mathrm{p}_{2}, \mathrm{p}_{5}\right\} & \mathrm{I}\left(\mathrm{p}_{2}\right)=\left\{\mathrm{t}_{2}\right\} \\
\mathrm{U}\left(\mathrm{t}_{3}\right)=\left\{\mathrm{p}_{3}\right\} & \mathrm{I}\left(\mathrm{p}_{3}\right)=\left\{\mathrm{t}_{2}, \mathrm{t}_{3}\right\} \\
\mathrm{U}\left(\mathrm{t}_{4}\right)=\left\{\mathrm{p}_{4}\right\} & \mathrm{I}\left(\mathrm{p}_{4}\right)=\left\{\mathrm{t}_{4}\right\} \\
\mu=(0,0, \ldots, 0) &
\end{array}
$$

\section{Markiranje Petrijevih mreža}

Markiranje Petrijeve mreže je postupak rasporeda i dodeljivanja određenog broja markera (token, marka) pozicijama mreže. Broj dodeljenih markera svakoj poziciji (M) ne sme da prekorači kapacitet pozicije $(\mathrm{K})$ što je definisano strukturom mreže. U grafu Petrijeve mreže kao marker koristi se crna tačka koja se postavlja u kružić pozicije. Broj markera, odnosno, kapacitet pozicije $\mathrm{K}$ može da se upiše u krug koji predstavlja poziciju. Težina orjentisane grane W dodeljuje se svakoj grani i predstavlja broj markera koji teku njome pri aktiviranju (okidanju, šaltovanju, iniciranju) tranzicije. Neobeležena grana, u skladu sa konvencijom, poseduje težinu jedan.

Petrijeve mreže kod kojih sve pozicije poseduju kapacitet jedan i sve orjentisane grane težinu jedan, zovu se mreže $\mathrm{P} / \mathrm{T}$ (pozicija/tranzicija), ili obične PM.

Navedene definicije objašnjavaju se primerom na slici 4 .

Primer 3.

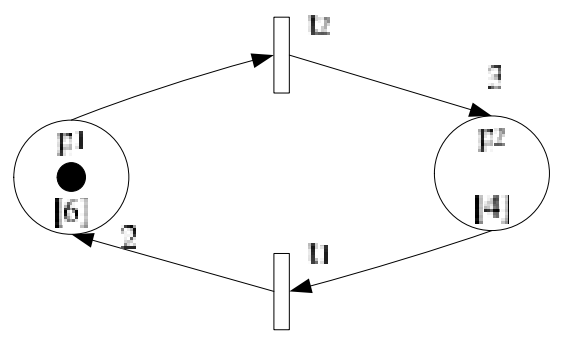




$$
\begin{aligned}
& \mathrm{P}=\left\{\mathrm{p}_{1}, \mathrm{p}_{2}\right\} \\
& \mathrm{T}=\left\{\mathrm{t}_{1}, \mathrm{t}_{2}\right\} \\
& \mathrm{F}=\left\{\left(\mathrm{p}_{1}, \mathrm{t}_{2}\right),\left(\mathrm{t}_{2}, \mathrm{p}_{2}\right),\left(\mathrm{p}_{2}, \mathrm{t}_{1}\right),\left(\mathrm{t}_{1}, \mathrm{p}_{1}\right)\right\} \\
& \mathrm{K}\left(\mathrm{p}_{1}\right)=6, \mathrm{~K}\left(\mathrm{p}_{2}\right)=4 \\
& \mathrm{~W}\left(\mathrm{p}_{1}, \mathrm{t}_{2}\right)=1, \mathrm{~W}\left(\mathrm{t}_{2}, \mathrm{p}_{2}\right)=3 \\
& \mathrm{~W}\left(\mathrm{p}_{2}, \mathrm{t}_{1}\right)=1, \mathrm{~W}\left(\mathrm{t}_{1}, \mathrm{p}_{2}\right)=2
\end{aligned}
$$

Slika 4. Markirana Petrijeva mreža

\section{Matrica incidencije PM}

Matrica incidencije:

$\mathrm{U}=\left[\mathrm{u}_{\mathrm{ij}}\right], \mathrm{i}=1,2, \ldots, \mathrm{n} ; \mathrm{j}=1,2, \ldots, \mathrm{q}, \quad$ obične

PM je definisana na sledeći način:

$$
\mathrm{u}_{\mathrm{ij}}=\left\{\begin{array}{l}
\mathrm{W}\left(\mathrm{t}_{\mathrm{j}}, \mathrm{p}_{\mathrm{i}}\right) \text { ako je } \mathrm{t}_{\mathrm{j}} \in{ }^{*} \mathrm{p}_{\mathrm{i}} \\
-\mathrm{W}\left(\mathrm{p}_{\mathrm{i}}, \mathrm{t}_{\mathrm{j}}\right) \text { ako je } \mathrm{t}_{\mathrm{j}} \in \mathrm{p}_{\mathrm{i}} \\
0 \mathrm{u} \text { ostalim slučajevima }
\end{array}\right.
$$

gde je: $\mathrm{n}$ - broj pozicija,

q - broj tranzicija Petrijeve mreže koja se razmatra,

$$
\mathrm{W}(\mathrm{x}, \mathrm{y}) \text { je težina grane }(\mathrm{x}, \mathrm{y}) \text {. }
$$

\section{Primer 4.}

Matrica incidencije koja odgovara PM sa slike 5. je matrica $U$ sa četiri reda $\mathrm{i}$ četiri kolone.

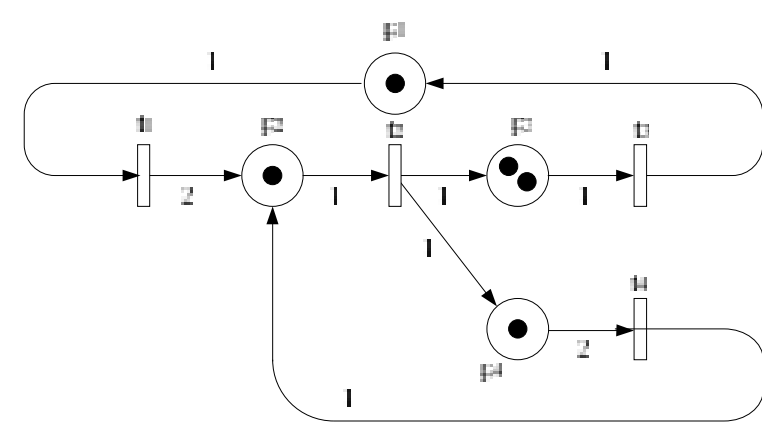

Slika 5. Petrijeva mreža

$$
\mathrm{U}=\left[\begin{array}{llll}
\mathrm{u}_{11} & \mathrm{u}_{12} & \mathrm{u}_{13} & \mathrm{u}_{14} \\
\mathrm{u}_{21} & \mathrm{u}_{22} & \mathrm{u}_{23} & \mathrm{u}_{24} \\
\mathrm{u}_{31} & \mathrm{u}_{32} & \mathrm{u}_{33} & \mathrm{u}_{34} \\
\mathrm{u}_{41} & \mathrm{u}_{42} & \mathrm{u}_{43} & \mathrm{u}_{44}
\end{array}\right]=\left[\begin{array}{ccc}
-1 & 0 & 1 \\
2 & -1 & 0 \\
0 & 1 & -1 \\
0 & 1 & 0
\end{array} .\right.
$$

Takođe u literaturi [49] se definišu i sledeće dve matrice:

$$
\mathrm{U}^{+}=\left[\mathrm{u}_{\mathrm{i}, \mathrm{j}}^{+}\right] \mathrm{i} \quad \mathrm{U}^{-}=\left[-\mathrm{u}_{\mathrm{i}, \mathrm{j}}^{-}\right]
$$

gde je

$$
u_{i, j}^{+}=\operatorname{Max}\left(0, u_{i, j}\right) i u_{i, j}^{-}=\operatorname{Min}\left(0, u_{i, j}\right)
$$

Za slučaj razmatrane matrice $U$ dobijaju se sledeće matrice:

$$
\mathrm{U}^{+}=\left[\begin{array}{llll}
0 & 0 & 1 & 0 \\
2 & 0 & 0 & 1 \\
0 & 1 & 0 & 0 \\
0 & 1 & 0 & 0
\end{array}\right] \quad \mathrm{i} \quad \mathrm{U}^{-}=\left[\begin{array}{llll}
1 & 0 & 0 & 0 \\
0 & 1 & 0 & 0 \\
0 & 0 & 1 & 0 \\
0 & 0 & 0 & 2
\end{array}\right]
$$

Može se utvrditi sledeća relacija:

$$
\mathrm{U}=\mathrm{U}^{+}-\mathrm{U}^{-}
$$

\section{Pravila upravljanja i dinamika Petrijevih mreža}

Kretanje markera kroz Petrijevu mrežu dešava se na osnovu pravila okidanja.

- Definicija koncesije tranzicije

Tranzicija ima koncesiju ako su ispunjeni uslovi:

$$
\begin{aligned}
& \mathrm{M}\left(\mathrm{p}_{\mathrm{j}}\right) \geq \mathrm{W}\left(\mathrm{p}_{\mathrm{j}}, \mathrm{t}_{\mathrm{i}}\right) \text { za } \forall \mathrm{p}_{\mathrm{j}} \in{ }^{\mathrm{o}} \mathrm{t}_{\mathrm{i}} \\
& \mathrm{M}\left(\mathrm{p}_{\mathrm{j}}\right) \leq \mathrm{K}\left(\mathrm{p}_{\mathrm{j}}\right)-\mathrm{W}\left(\mathrm{t}_{\mathrm{i}}, \mathrm{p}_{\mathrm{i}}\right) \text { za } \forall \mathrm{p}_{\mathrm{j}} \in \mathrm{t}_{\mathrm{i}}^{\mathrm{o}}
\end{aligned}
$$

- Uslovi za okidanje tranzicije:

- Na svim prethodnim pozicijama treba da se nalaze najmanje toliko markera koliko se pri okidanju mora oduzeti

- Svaka naredna pozicija mora da od tranzicije predate markere oduzme

Izložena pravila ilustruju se kroz primer na slikama 6. i 7. 


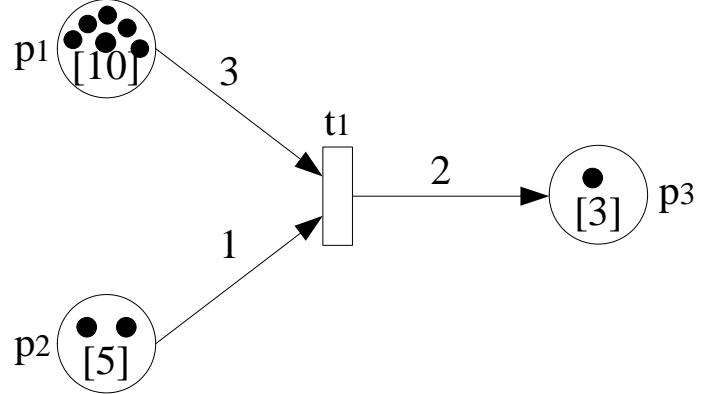

Slika 6. Stanje pre okidanja tranzicije $t_{1}$

Postupak okidanja tranzicije $\mathrm{t}_{1}$ je sledeći:

1. Sa pozicije $\mathrm{p}_{1}$ uklanjaju se tri markera (zbog težine 3 )

2. Sa pozicije $\mathrm{p}_{2}$ uklanja se jedan marker (zbog težine 1)

3. Poziciji $\mathrm{p}_{3}$ dodaju se dva markera (zbog težine 2)

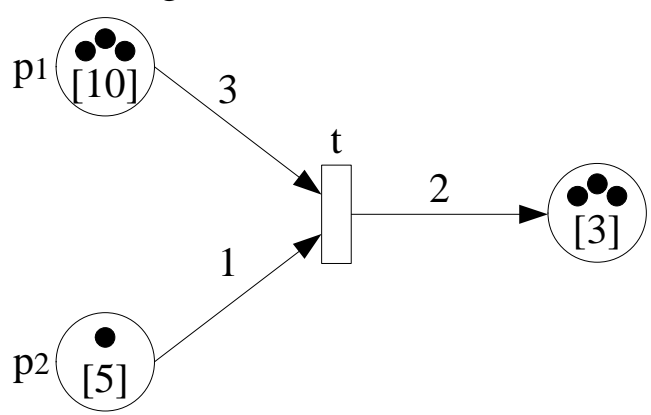

\section{Slika 7. Stanje posle okidanja tranzicije $t_{1}$}

Dinamika Petrijevih mreža se može razmatrati ukoliko se uvede sledeći sistem označavanja:

${ }^{o} t$ - skup ulaznih pozicija za tranziciju $t$, $(\mathrm{p}, \mathrm{t}) \in \mathrm{A}$

$\mathrm{t}^{\mathrm{O}}$ - skup izlaznih pozicija za tranziciju $\mathrm{t}$, $(\mathrm{t}, \mathrm{p}) \in \mathrm{A}$

${ }^{o} \mathrm{p}$ - skup ulaznih tranzicija pozicije $\mathrm{p}$, $(\mathrm{t}, \mathrm{p}) \in \mathrm{A}$

$\mathrm{p}^{\mathrm{o}}$ - skup izlaznih tranzicija za poziciju $\mathrm{p}$, $(p, t) \in A$

Za ovako definisane skupove formalni opis ima oblik:

$$
\begin{aligned}
& { }^{o} \mathrm{t}=\{\text { p, u.p.t } \in \mathrm{P} i(p, t) \in A\} \\
& \mathrm{t}^{\mathrm{o}}=\{\text { p,i.p.t } \in \mathrm{P} i(\mathrm{t}, \mathrm{p}) \in \mathrm{A}\} \\
& { }^{\mathrm{o}} \mathrm{p}=\{\mathrm{t}, \text { u.t.p } \in \mathrm{T} \mathrm{i}(\mathrm{t}, \mathrm{p}) \in \mathrm{A}\} \\
& \mathrm{p}^{\mathrm{o}}=\{\text { t, i.t.p } \in \mathrm{T} \mathrm{i}(\mathrm{p}, \mathrm{t}) \in \mathrm{A}\}
\end{aligned}
$$

Kaže se da je tranzicija osposobljena za bilo koje $\mathrm{p} \in{ }^{\mathrm{o}} \mathrm{t}, \mathrm{M}(\mathrm{p}) \geq \omega(\mathrm{p}, \mathrm{t})$. Drugim rečima, $\mathrm{t}$ je osposobljena ako svaka od njegovih ulaznih pozicija sadrži najmanje markera kao težina grane koja spaja ovu poziciju sa t. Zato, u slučaju obične Petrijeve mreže, $t$ je osposobljeno ako svaka od njegovih ulaznih pozicija sadrže najmanje jedan marker.

Ako je $t \in T$ osposobljena, ona može biti okinuta (startovana, opaljena). Okidanje (startovanje, opaljenja) pozicije sastoji se u:

- uklanjanju $\omega(\mathrm{p}, \mathrm{t})$ markera iz svake $\mathrm{p} \in{ }^{\mathrm{o}} \mathrm{t}$

- pridruživanje $\omega(\mathrm{t}, \mathrm{p})$ markera svakoj $\mathrm{p} \in{ }^{\mathrm{o}} \mathrm{t}$

Formalno, okidanje tranzicije $\mathrm{t}$ sastoji se $\mathrm{u}$ transformaciji početnog markiranja $M o$ Petrijeve mreže u markiranje $M$ koje je definisano na sledeći način:

$$
M(p)=\left\{\begin{array}{r}
M o(p)-\omega(p, t) \text { ako je } p \in^{o} t \\
M o(p)+\omega(t, p) \text { ako je } p \in^{o} t \\
M o(p) \text { na drugi način }
\end{array}\right.
$$

Označiće se sa R(Mo) skup markiranja koji je dostižan iz M pomoću okidanja sekvence tranzicija.

Dinamika Petrijevih mreža biće objašnjena na Primeru 5, na slici 8 .

Primer 5.

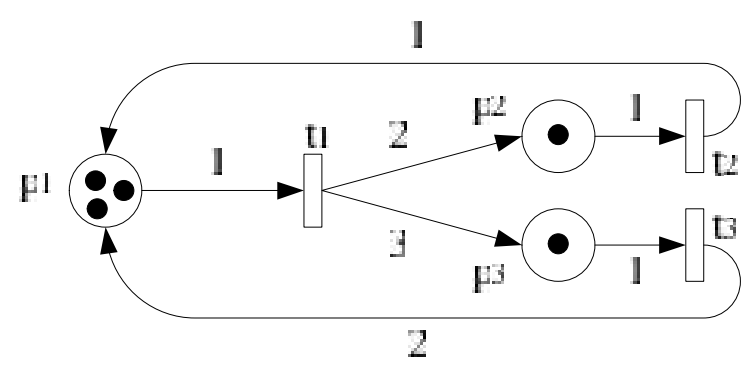

Slika 8. Petrijeva mreža

Početno (inicijalno) markiranje zadate Petrijeve mreže je $\mathrm{Mo}=[3,1,1]$. Nakon okidanja tranzicije markiranje postaje $\mathrm{M}_{1}=[5,2,3]$ na sledeći način:

- okidanjem $t_{1}$ uklanja se jedan marker iz pozicije $\mathrm{p}_{1}$ a dodaju dva markera $\mathrm{u}$ poziciji $\mathrm{p}_{2}$ i tri $u \mathrm{p}_{3}$ 
- okidanjem $t_{2}$ uklanja se jedan mareker iz $\mathrm{p}_{2} \mathrm{i}$ dodaje jedan marker $\mathrm{u} \mathrm{p}_{1}$

- okidanjem tranzicije $t_{3}$ uklanja se jedan marker iz $\mathrm{p}_{3}$ i dodaju dva $u$ $\mathrm{p}_{1}$

Izračunavanje se može prikazati na sledeći način:

$\begin{array}{lccc}\text { Markiranje Mo } & \mathrm{p}_{1} & \mathrm{p}_{2} & \mathrm{p}_{3} \\ & 3 & 1 & 1 \\ \text { Okidanje } \mathrm{t}_{1} & -1 & 2 & 3 \\ {\text { Okidanje } \mathrm{t}_{2}} & 1 & -1 & \\ \text { Okidanje t }_{3} & 2 & & -1 \\ \left.\text { Ukupno (markiranje } \mathrm{M}_{1}\right) & 5 & 2 & 3\end{array}$

Upoređivanjem $M_{1}$ sa Mo, nalaze se dva markera više $u p_{1}$ i $p_{3}$, a jedan marker više $u$ $\mathrm{p}_{2}$.

\section{Predstavljanje i modeliranje proizvodnih sistema i logičkih struktura}

Za predstavljanje i modeliranje sistema koji imaju logičku strukturu neophodno je definisati dva osnovna pojma: događaje i uslove. Funkcionisanje sistema sastoji se u ostvarivanju niza događaja, odnosno, niza definisanih dejstava. Za nastanak događaja neophodno je ispunjenje drugih uslova koji se nazivaju preduslovi. Nastanak događaja može proizvesti narušavanje preduslova i ispunjenje nekih drugih uslova koji se nazivaju postuslovi.

Modeliranje funkcionisanja neke logičke strukture primenom Petrijevih mreža izvodi se na sledeći način: događaji se predstavljaju tranzicijama, a uslovi pozicijama. Preduslovi događaja predstavljaju se ulaznim pozicijama odgovarajuće tranzicije a postuslovi izlaznim pozicijama. Nastanak događaja predstavlja se aktiviranjem (iniciranjem, okidanjem) tranzicije. Ispunjenje uslova predstavljeno je postojanjem markera (tačaka) u odgovarajućim pozicijama.

\section{Primer 6.}

Modeliranje logičke strukture objašnjava se na primeru automata za utiskivanje datuma (signiranje) na čepu boce. Automat se nalazi u stanju očekivanja sve dok se na transportnoj traci ne pojavi čep. Tada se izvršava utiskivanje datuma a nakon toga čep se šalje na montažu.

Za slučaj ovog automata definišu se uslovi i događaji na sledeći način:

Uslovi:

a) automat čeka;

b) čep je stigao i čeka;

c) automat izvršava utiskivanje;

d) utiskivanje je izvršeno.

Događaji:

1. čep je stigao;

2. automat otpočinje izvršenje utiskivanja;

3. automat završava utiskivanje;

4. čep se šalje na montažu.

Tablica događaja:

$\begin{array}{ccc}\text { Događaji } & \text { Preduslovi } & \text { Postuslovi } \\ 1 & \text { nema } & \text { b } \\ 2 & \text { a, b } & \text { c } \\ 3 & \text { c } & \text { d, a } \\ 4 & \text { d } & \text { nema }\end{array}$

$\mathrm{Na}$ osnovu ovako definisanih događaja i uslova opisani sistem se može modelirati pomoću Petrijeve mreže u kojoj su događaji - tranzicije a uslovi - pozicije. Na slici 9. predstavljen je odgovarajući model.

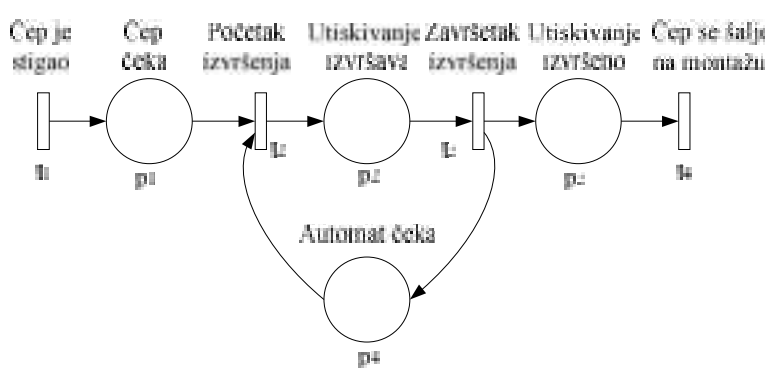

Slika 9. Petrijeva mreža automata za utiskivanje datuma

U ovom poglavlju izložene su neke osnovne postavke iz teorije Petrijevih mreža koje će služiti kao baza za njihovu dalju primenu u 
oblasti analize i sinteze konačnih automata i razmatranja procesa optimizacije njihove strukture.

\section{Dekompozicija proizvodnih sistema}

Mogu se razbiti, odnosno, dekomponovati PM koje sadrže tranzicije izvora i tranzicije ponora. Ovakve PM mogu da se koriste npr. za modeliranje unutrašnjeg transporta kod proizvodnih procesa (donošenje i odnošenje radnih predmeta, tokovi materijala i sl.) [1].

Postupak dekompozicije PM objašnjava se na primeru utvrđivanja $\mathrm{t}$ - invarijanti, odnosno određivanja broja derivacija početne, zadate PM.

\section{Definicija 3.}

Neka $\mathrm{W}$ bude $\mathrm{t}$ - invarijanta Petrijeve mreže M. Kaže se da će Petrijeva mreža $\mathrm{M}_{\mathrm{W}}$ biti $\mathrm{W}$ - derivacija od M ako je:

1. Skup tranzicija $\mathrm{N}_{\mathrm{W}}$ je $\|\mathrm{W}\|$.

2. Za neko $t \in\|W\|,{ }^{\circ}$ i t ${ }^{o}$ su neke od $\mathrm{N}$ i $\mathrm{N}_{\mathrm{W}}$.

3. Težine neke grane od $\mathrm{N}_{\mathrm{W}}$ je neka težina od neke grane u N.

Vektor W sa jednim redom i q kolona (q je broj tranzicija PM) i sa nenegativnim brojem elemenata je t-invarijanta ako je $\mathrm{U} \cdot \mathrm{W}^{\mathrm{t}}=0$, gde je U matrica incidencije [1].

\section{Primer 7.}

Razmatra se PM prikazana na slici 10. Ona predstavlja jedan ciklični deo proizvodnog sistema. Sirov materijal koji stiže u sistem u datoj tački $\left(\mathrm{t}_{1}\right)$ se transformiše u završni proizvod $\left(\mathrm{t}_{2}\right)$ i napušta sistem u pravcu dva puta $\left(t_{3}\right.$ ili $\left.t_{4}\right)$.

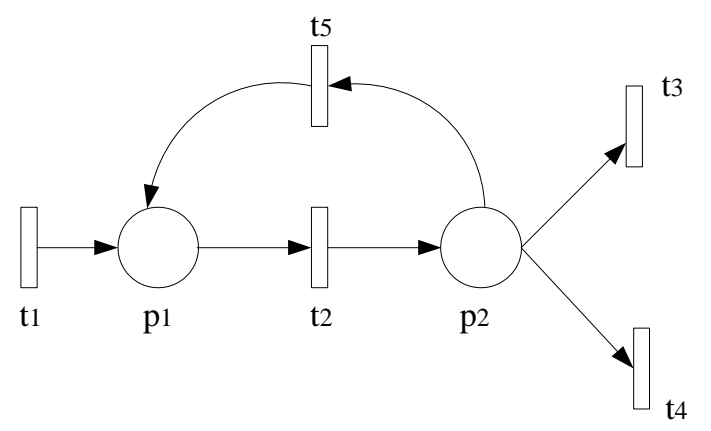

Slika 10. Model cikličnog proizvodnog sistema
Incidentna matrica (matrica incidencije) Petrijeve mreže sa Slike 10. je U.

$$
\mathrm{U}=\left[\begin{array}{cccccc}
\mathrm{t}_{1} & \mathrm{t}_{2} & \mathrm{t}_{3} & \mathrm{t}_{4} & \mathrm{t}_{5} \\
0 & 1 & 0 & 0 & 1 \\
0 & -1 & -1 & -1
\end{array}\right] \begin{aligned}
& \mathrm{p}_{1} \\
& \mathrm{p}_{2}
\end{aligned}
$$

Ako je $\mathrm{W}=\left[\mathrm{w}_{1}, \mathrm{w}_{2}, \mathrm{w}_{3}, \mathrm{w}_{4}, \mathrm{w}_{5}\right] \quad \mathrm{t}$ invarijanta tada je $U \cdot W^{t}=0$, što vodi do sistema:

$$
\begin{aligned}
& \begin{array}{llll}
\mathrm{w}_{1}-\mathrm{w}_{2} & \mathrm{w}_{5}=0
\end{array} \\
& \mathrm{w}_{2} \quad-\mathrm{w}_{3} \quad-\mathrm{w}_{4} \quad-\mathrm{w}_{5} \quad=0
\end{aligned}
$$

Neke od $\mathrm{t}$ - invarijanti su:

$$
\begin{aligned}
& \mathrm{W}_{1}=[0,1,0,0,1] \\
& \mathrm{W}_{2}=[1,1,1,0,0] \\
& \mathrm{W}_{3}=[1,1,0,1,0]
\end{aligned}
$$

Petrijeve mreže koje su $\mathrm{W}_{1}, \mathrm{~W}_{2}$ i $\mathrm{W}_{3}$ derivacije iz prethodnog primera predstavljene su na slici 11.

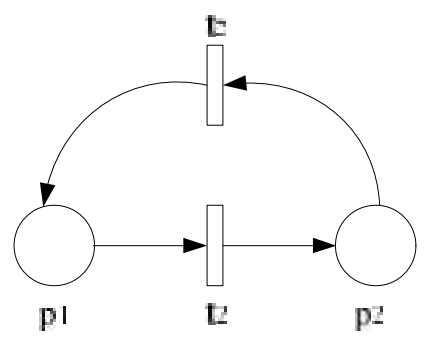

a) $\mathrm{W}_{1}$ - derivacija od $\mathrm{PM}$

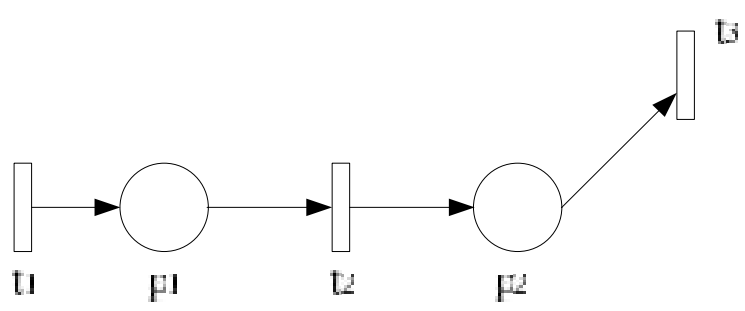

b) $\mathrm{W}_{2}$ - derivacija od $\mathrm{PM}$

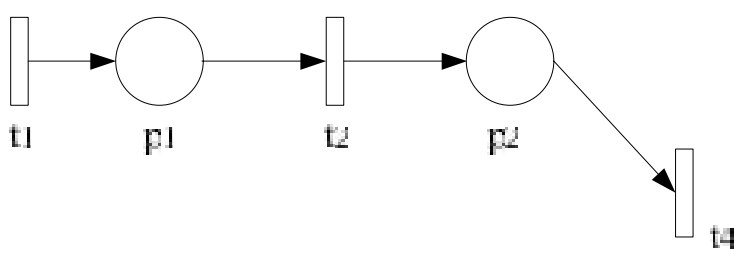

c) $\mathrm{W}_{3}$ - derivacija od $\mathrm{PM}$ 
Dobijene derivacije predstavljaju delove početnog Petrijevog grafa proizvodnog sistema koji je dekompovan.

\section{Zaključak}

Modeliranje i simulacije proizvodnih sistema i sličnih struktura pomoću Petrijevih mreža i njihovih grafova predstavlja efektan postupak koji se koristi pri analizi njihovih ponašanja. Primena nekih osobina Petrijevih grafova omogućava dalje proučavanje i eventualnu optimizaciju struktura ovih sistema.

\section{Bibliografija}

1. Proth Jean-Marie, Xie Xiaolan, „Petri Nets“, John Wiley \& Sons, Chichester, England, 1996.

2. Rančić M., Živković D., Jovanić D., „Modeliranje logičkih struktura primenom Petrijevih mreža“, Zbornik radova, 31. Jupiter konferencija, Mašinski fakultet Beograd, Beograd, 2005.

3. Rančić M., „Application of Petri Net Decomposition Method for the Modelling and Analysis of Manufacturing Processes“, Proceeding, SIE 2009, Faculty of Mechanical Engineering University of Belgrade, 2009.

\section{Istorija rada:}

Rad primljen: 30.04.2013.

Prva revizija: 21.05.2013.

Prihvaćen: 01.06.2013. 